\title{
Current views and advances on Paediatric Virology: An update for paediatric trainees (Review)
}

\author{
IOANNIS N. MAMMAS ${ }^{1}$, ANNE GREENOUGH ${ }^{2}$, MARIA THEODORIDOU $^{3}$, ANNA KRAMVIS $^{4}$, ILIANA CHRISTAKI ${ }^{5}$, \\ CHRYSSIE KOUTSAFTIKI $^{6}$, MARIA KOUTSAKI ${ }^{7}$, DIMITRA M. PORTALIOU ${ }^{8}$, GEORGIA KOSTAGIANNI ${ }^{9}$, \\ PARASKEVI PANAGOPOULOU ${ }^{10}$, GEORGE SOURVINOS ${ }^{1}$ and DEMETRIOS A. SPANDIDOS ${ }^{1}$
}

\begin{abstract}
${ }^{1}$ Department of Clinical Virology, University of Crete School of Medicine, Heraklion 71003, Greece; ${ }^{2}$ Division of Asthma, Allergy and Lung Biology, King's College London, London SE5 9RS, UK; ${ }^{3}$ First Department of Paediatrics, 'Aghia Sophia' Children's Hospital, University of Athens School of Medicine, Athens 11527, Greece; ${ }^{4}$ Hepatitis Virus Diversity Research Unit, School of Clinical Medicine, Faculty of Health Sciences, University of the Witwatersrand, Johannesburg 2193, South Africa; ${ }^{5}$ Edinburgh Medical School, University of Edinburgh, Edinburgh EH16 4TJ, UK; ${ }^{6}$ Paediatric Intensive Care Unit (PICU), 'Penteli' Children's Hospital, Penteli 15236; ${ }^{7}$ Department of Paediatrics, University Hospital of Heraklion, Heraklion 71110; ${ }^{8}$ Institute of Vision and Optics (BEMMO-IVO), University of Crete School of Medicine, Heraklion 71003; ${ }^{9}$ Department of Otorhinolaryngology - Head and Neck Surgery, 'Thriassio' General Hospital, Elefsina 19200; ${ }^{10} 4$ th Department of Paediatrics, Aristotle University of Thessaloniki, 'Papageorgiou' General Hospital, Thessaloniki 56403, Greece
\end{abstract}

Received October 12, 2015; Accepted November 24, 2015

DOI: 10.3892/etm.2015.2890

\begin{abstract}
Paediatric Virology is a bold new scientific field, which combines Paediatrics with Virology, Epidemiology, Molecular Medicine, Evidence-based Medicine, Clinical

Correspondence to: Professor Demetrios A. Spandidos, Department of Clinical Virology, University of Crete School of Medicine, Heraklion 71003, Greece

E-mail: spandidos@spandidos.gr
\end{abstract}

Abbreviations: AFP, acute flaccid paralysis; AIDS, acquired immunodeficiency syndrome; ALTO, alternative tumor antigen open reading frame; ASD, autism spectrum disorders; BPD, bronchopulmonary dysplasia; CMV, cytomegalovirus; DNA, deoxyribonucleic acid; EBV, Epstein Barr virus; ED, emergency department; EEA, endoscopic endonasal approach; ELISA, enzyme linked immunosorbent assay; $\mathrm{EV}$, Ebola virus; $\mathrm{HBV}$, hepatitis B virus; $\mathrm{HBcAg}$, hepatitis B capsid protein; $\mathrm{HBeAg}$, hepatitis $\mathrm{B}$ e antigen; hMPV, human metapneumovirus; HPV, human papillomavirus; HRV, human rhinovirus; HSV, herpes simplex virus; IM, infectious mononucleosis; IPV, inactivated polio vaccine; LRTI, lower respiratory tract infection; LT, large tumor; MCC, Merkel cell carcinoma; MCPyV, Merkel cell polyomavirus; MMR, measles, mumps and rubella; NCRR, non-coding regulatory region; NICU, Neonatal Intensive Care Unit; OPV, oral polio vaccine; PICU, Paediatric Intensive Care Unit; PPE, personal protective equipment; PVSG, Paediatric Virology Study Group; RCPCH, Royal College of Paediatrics and Child Health; RNA, ribonucleic acid; RRP, recurrent respiratory papillomatosis; RSV, respiratory syncytial virus; SARS, severe acute respiratory syndrome; SNP, single nucleotide polymorphism; sT, small tumor; TLM, transoral laser microsurgery; VP 1-3, viral protein 1-3; VZV, varicella-zoster virus; WHO, World Health Organization; WNV, west Nile virus; WPV, wild-type poliovirus

Key words: Paediatric Virology, viral infections, human papilloma virus, respiratory syncytial virus, hepatitis $\mathrm{B}$, poliomyelitis, Ebola, measles, mumps, rubella, infectious mononucleosis, Merkel cell polyomavirus
Governance, Quality Improvement, Pharmacology and Immunology. The Workshop on Paediatric Virology, which took place on Saturday October 10, 2015 in Athens, Greece, provided an overview of recent views and advances on viral infections occurring in neonates and children. It was included in the official programme of the 20th World Congress on Advances in Oncology and the 18th International Symposium on Molecular Medicine, which attracted over 500 delegates from the five continents. During the Workshop, the topics covered included the challenges of vaccine implementation against human papillomaviruses in countries under financial crisis, strategies for eradicating poliomyelitis and its 60th vaccine anniversary, as well as the debate on the association between autism and vaccination against measles, mumps and rubella. Among the non-vaccine related topics, emphasis was given to viral infections in prematurely born infants and their long-term outcomes, new paediatric intensive care management options for bronchiolitis related to respiratory syncytial virus, the clinical implications of hepatitis B virus and cytomegalovirus genotyping, the Ebola virus threat and preparedness in Paediatric Emergency Departments, oral, oropharynx, laryngeal, nasal and ocular viral infections and Merkel cell polyomavirus as a novel emerging virus of infancy and childhood. In this review, we provide selected presentations and reports discussed at the Workshop.

\section{Contents}

1. Introduction

2. Workshop on Paediatric Virology

3. Update on current views and advances on Paediatric Virology 


\section{Introduction}

The history of paediatric infectious diseases closely parallels the history of Paediatrics, as infections remain the major causes of childhood morbidity and mortality $(1,2)$. Viral paediatric infectious diseases are characterised by a great heterogeneity of clinical manifestations due to the unique characteristics of the neonatal period and childhood. Almost 50 years ago, Paediatric Virology was not considered an isolated discipline and was included in the paediatric infectious diseases section of the scientific field of Paediatrics (3). However, during the past two decades, new advances in the field of Clinical Virology and Molecular Medicine have expanded the level of knowledge on the prevention, diagnosis and treatment of viral infections occurring in infancy and childhood. For this reason, although additional subspecialists in several fields may be diminishing (4), Paediatric Virology as a bold new scientific field can combine Paediatrics with Virology, Epidemiology, Molecular Medicine, Evidence-based Medicine, Clinical Governance, Quality Improvement, Pharmacology and Immunology (Fig. 1).

To date, paediatric infectious diseases professionals have achieved a distinct role within the scientific field of Paediatrics and their contribution to tertiary paediatric care is valued (2). Their current clinical and research aims are to resolve important public health issues in both developed and developing countries. Furthermore, new emerging diseases, such as severe acute respiratory syndrome (SARS), west Nile virus (WNV) and Ebola virus (EV) infections, require new prevention strategies and therapeutic protocols. In addition, paediatric infectious diseases professionals are involved in specialised paediatric care and in the follow-up of children with a history of viral infections, such as viral meningitis or acquired immunodeficiency syndrome (AIDS), who survive to adolescent years and beyond, requiring advanced medical care and technological services. Moreover, newfound social issues have arisen, including the recent anti-vaccination wave, the financial crisis and the unprecedented immigration occurring globally and in Mediterranean countries, in particular (5). These developments and changes definitely highlight the demand for the continuous education of paediatric health professionals, informing them of the ongoing advances in paediatric care and management strategies involved in the discipline of Paediatric Virology $(6,7)$.

\section{Workshop on Paediatric Virology}

The 20th World Congress on Advances in Oncology and the 18th International Symposium on Molecular Medicine was held in Athens (Greece) and was attended by $>500$ participants from the five continents (8). This annual scientific meeting attracted its largest number of delegates to date and over a period of three days, up-to-date basic and clinical research findings on Molecular Medicine and Oncology were presented and discussed. For the first time this year, during the third day of the meeting, participants had the chance to participate in the Workshop on Paediatric Virology, with the theme 'Paediatric Virology: from the lab to clinical practice' (Fig. 2). This Workshop gathered world experts on Paediatrics, Neonatology, Virology, Vaccinology, Epidemiology, Microbiology and Public Health. It was co-chaired by Professor Anne Greenough, Professor of Neonatology and Clinical Respiratory Physiology at King's
College London in London (UK) and Vice-President of the Royal College of Paediatrics and Child Health (RCPCH), Professor Anna Kramvis, Research Professor of Molecular Virology at the University of the Witwatersrand in Johannesburg (South Africa) and Professor Maria Theodoridou, Professor of Paediatrics at the 'Aghia Sophia' Children's Hospital in Athens (Greece). The Workshop was enthusiastically supported by the Department of Clinical Virology, School of Medicine, University of Crete in Heraklion (Greece) and the First Department of Paediatrics of the School of Medicine at the University of Athens in Athens (Greece).

The initial idea for the birth of this Workshop was inspired in 2007 at the Wirral University Teaching Hospital in Wirral (UK), where cytomegalovirus (CMV)-positive twins were treated at the local Neonatal Intensive Care Unit (NICU) (9), requiring the collaboration of an extended scientific network in Merseyside and Manchester (UK) for the management of this neonatal viral infection. Two years later, in October 2009, during the oral session at the 14th World Congress on Advances in Oncology and the 12th International Meeting in Molecular Medicine, which was devoted to human papilloma virus (HPV) infection in childhood (10) and chaired by Professor Maria Theodoridou, Professor of Paediatrics at the 'Aghia Sophia' Children's Hospital in Athens (Greece), this idea was re-enforced by a group of young paediatric trainees and junior researchers, leading to the creation of the Paediatric Virology Study Group (PVSG). The fundamental aim of the PVSG was to provide an array of scientific and educational activities, bringing together Virology with Paediatrics within a single entity. Covering Basic Sciences and Clinical Medicine, the PVSG was open to scientists interested in the field of Paediatric Virology, either as basic scientists, researchers and virologists or as medical students, paediatric trainees, general paediatricians, paediatric infectious diseases physicians and allied health professionals. Six years later, on October 2015, the PVSG had the great honour to coordinate the 'Workshop on Paediatric Virology' as an official session of the 20th World Congress on Advances in Oncology and the 18th International Meeting in Molecular Medicine. This Workshop was dedicated to promoting international scientific exchange and cooperation of both clinicians and researchers on Paediatric Virology and improving biomedical research and paediatric medical practice on viral infections occurring in childhood. In this review, we present an update on selected topics presented at the Workshop.

\section{Update on current views and advances on Paediatric Virology}

Viral infections and long-term outcomes of prematurely born infants. Respiratory syncytial virus (RSV) is a common respiratory pathogen in young children (11). Between 1 and $2 \%$ of infected children will require hospitalisation and up to $8 \%$ of those hospitalised will require mechanical ventilation. Numerous studies (12-16) have demonstrated that infants born at term, who were previously healthy, subsequent to an RSV lower respiratory tract infection (LRTI), develop chronic respiratory morbidity. There are many risk factors for severe acute RSV infection, which include being born prematurely and having developed bronchopulmonary dysplasia (BPD). Greenough et al (12) have demonstrated that up to school age, 


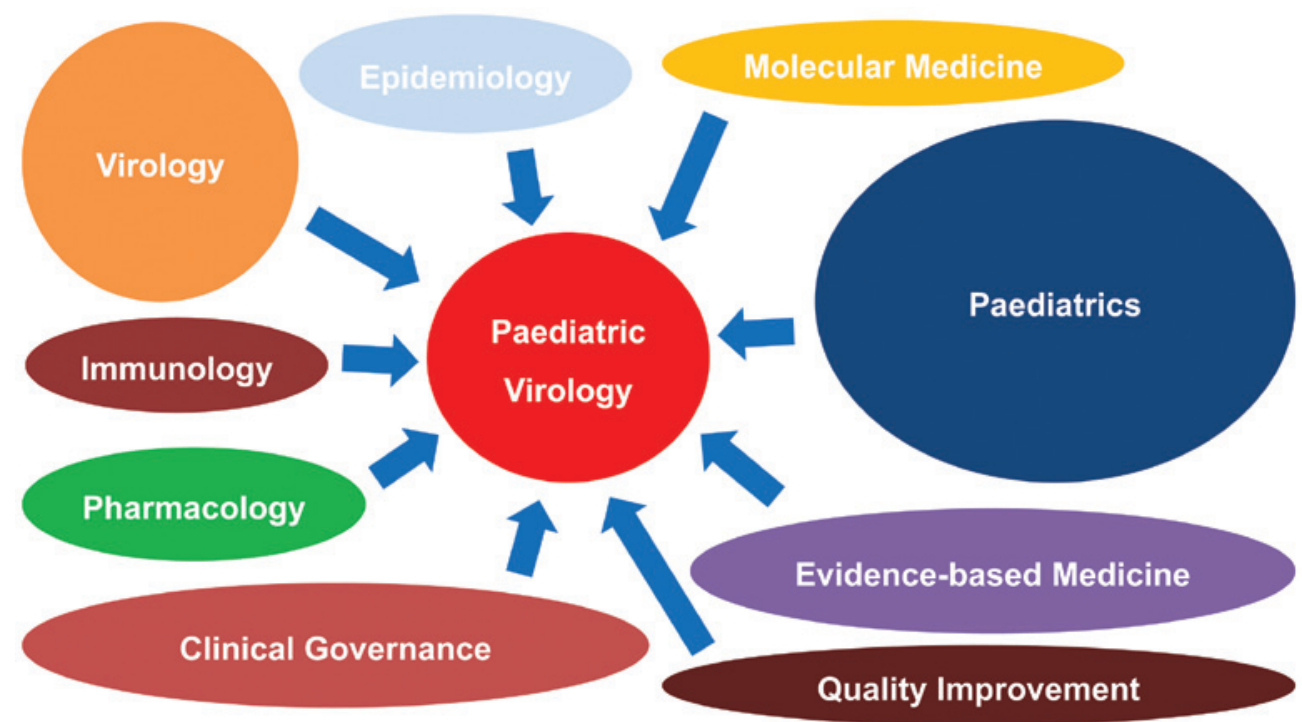

Figure 1. Paediatric Virology involves the scientific fields of Paediatrics, Virology, Epidemiology, Molecular Medicine, Evidence-based Medicine, Clinical Governance, Quality Improvement, Pharmacology and Immunology.

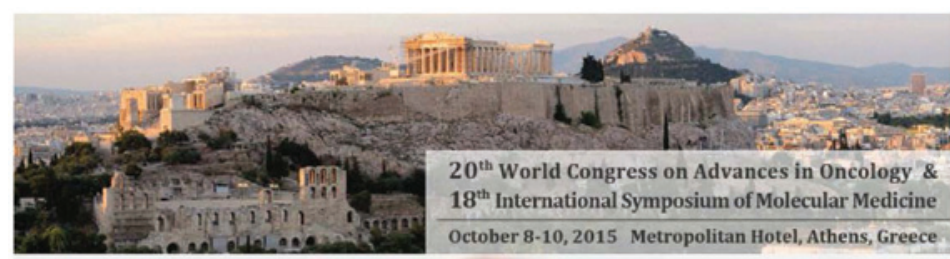

\section{WORKSHOP ON}

\section{PAEDIATRIC VIROLOGY}
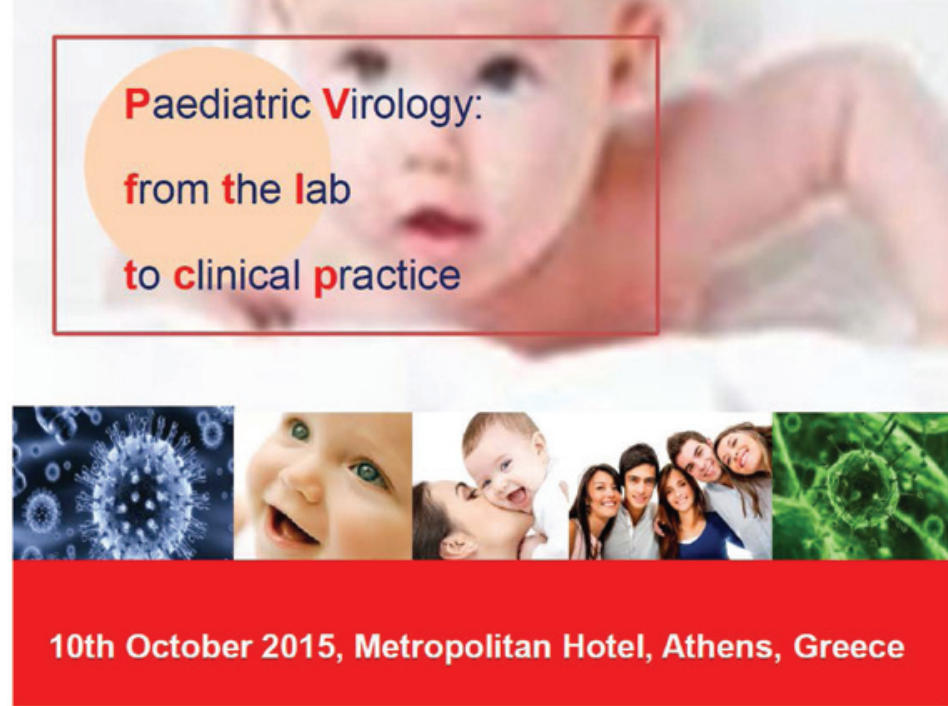

Figure 2. Workshop on Paediatric Virology with the theme 'Paediatric Virology: from the lab to clinical practice', Athens, Saturday, October 10, 2015.

those prematurely born children, who had developed BPD and an RSV LRTI requiring hospitalisation in infancy, had increased healthcare utilisation and worse lung function, particularly affecting small airways, than children with BPD, who 
had not been hospitalised due to RSV. Healthcare utilisation in the first two years after birth was also shown to be increased even in moderately prematurely born infants (32-35 weeks of gestation), who had were hospitalised due to RSV (13). In two prospectively followed cohorts, one very prematurely born cohort (14) and the other, which included pre-term infants of a wide range of gestational ages (24-35 weeks), respiratory morbidity was greater during infancy in those who had had an RSV LRTI $(15,16)$. In the very prematurely born cohort, subsequent respiratory morbidity was increased after an RSV LRTI regardless of whether hospitalisation was required or the infant had BPD (14). The prematurely born infants, who required hospitalisation due to an RSV LRTI, had poorer premorbid lung function (17). It has also been identified that prematurely born infants may have a genetic predisposition to developing RSV LRTIs. In addition, single nucleotide polymorphisms (SNPs) in several genes were found to be associated with chronic respiratory morbidity during infancy and reduced lung function at one year following an RSV LRTI (18). Other respiratory viral infections also adversely influence respiratory outcomes during infancy in those born prematurely, including human metapneumovirus (hMPV) and human rhinovirus (HRV), particularly HRV-C (19).

Defeating polio: Vaccine anniversary (1955-2015). Poliomyelitis is an acute infectious disease affecting humans, occurring particularly in children, which is caused by small ribonucleic acid (RNA) viruses of the enterovirus group of the family Picornavidae (20-26). Three antigenically distinct strains (strains 1, 2 and 3) are known, with-type 1 accounting for $85 \%$ of cases. The clinical manifestations of the disease vary greatly. Most cases are asymptomatic; paralytic illness is rare, affecting $<1 \%$ of infected individuals. The year 2015 is the 60th anniversary since Jonas Salk launched the inactivated polio vaccine (IPV), enabling children to be protected against the crippling disease of poliomyelitis. With the development of the oral polio vaccine (OPV) by Albert Sabin in 1961, the world was given the tools, with which to stop outbreaks, strengthen and build immunity, to ensure that children can grow up without the threat of polio. The combination of OPV and IPV led to the eradication of polio in the Americas, the western Pacific and Europe. Today, $80 \%$ of the world population lives in polio-free regions. Nevertheless, Pakistan, Afghanistan and Nigeria are countries where polio is still categorised as an endemic viral infection. It should be noted that in 2013-2014 an upsurge of polio in areas, which were considered polio-free, occurred. The confirmed circulation of wild-type poliovirus (WPV) in Israel and the outbreak of acute flaccid paralysis (AFP) in Syria mean that there is a high risk of the disease being reintroduced into Europe. Europe should implement a prevention policy, which is based on enhancing the vaccination of resident and refugee populations, strengthening surveillance and being prepared to rapidly respond to the identification of polio. In Greece, there is a national action plan, which includes programmes to sustain high levels of polio immunisation coverage, AFP surveillance and actions in the event of a suspected or confirmed poliomyelitis case. Fighting polio with vaccination has been one of the most successful public health programmes in history, reducing the number of polio cases by $99 \%$, making possible the expectation towards disease eradication.
Clinical implications of hepatitis $B$ virus (HBV) genotypes in Paediatrics. Even though a successful vaccine against HBV has been implemented in 184 countries, the eradication of HBV is still not on the horizon (27). According to the World Health Organization (WHO), there are 240 million chronic carriers of the virus, globally (28). The risk of developing chronic hepatitis ranges from $>90 \%$ in newborns of hepatitis $\mathrm{B}$ e antigen ( $\mathrm{HBeAg}$ )-positive mothers, 25-35\% in children under the age of 5 and $<5 \%$ in adults (29). HBeAg, a non-particulate viral protein, is conventionally considered a marker of HBV replication (30). This is the only antigen of $\mathrm{HBV}$, which can cross the placenta (31), leading to the specific unresponsiveness of helper $\mathrm{T}$ cells to the hepatitis $\mathrm{B}$ capsid protein $(\mathrm{HBcAg})$ and $\mathrm{HBeAg}$ in newborns of $\mathrm{HBeAg}$-positive mothers (32). HBeAg is tolerated in utero and acts as a tolerogen after birth (33). Thus, perinatal transmission is frequent when mothers are $\mathrm{HBeAg}$-positive, whereas it occurs significantly less frequently when mothers are HBeAg-negative (34-36).

Sequence heterogeneity is a characteristic of HBV, the prototype member of the family Hepadnaviridae (37). Based on an intergroup divergence of $>7.5 \%$ across the complete genome, HBV has been classified phylogenetically into at least 9 genotypes. With between $\sim 4$ and $8 \%$ intergroup nucleotide divergence across the complete genome and good bootstrap support, genotypes A-D, F, H and I are further classified into subgenotypes. HBV genotypes and in some cases subgenotypes have a distinct geographical distribution both globally and locally (37). The different genotypes/subgenotypes can develop different mutations in the regions of the HBV genome, which code for $\mathrm{HBeAg}$ and the envelope proteins. These differences can be related to the role of the HBV genotypes, to their mode of transmission, to the clinical manifestation of the disease following HBV infection and to their response to antiviral therapy. Thus, the genotypes/subgenotypes of HBV may be responsible for the different modes of transmission and natural history of infection in children, noted in different regions of the world, where distinct genotypes/subgenotypes prevail.

Implementation of vaccination against HPV in a country under financial crisis. Despite the invention of the Pap smear test by George N. Papanicolaou almost 90 years ago, HPV is considered the most frequent carcinogen in humans, causing approximately 530,000 cases of cervical cancer per annum, with the majority of cases occurring in developing countries (38-40). The link between this deoxyribonucleic acid (DNA) virus and cervical cancer was firstly suspected in the early 1970s by Professor Harald zur Hausen, who in 2008 received the Nobel Prize in Physiology and Medicine (41). In the same year, two vaccines against HPV, the bivalent HPV 16/18 and the quadrivalent HPV 6/11/16/18, were implemented into clinical practice in several countries, worldwide (42). However, despite the significant calculated expected health benefits following the implementation of HPV vaccination programmes, current trends indicate low HPV vaccination uptake among female adolescents in several countries in Europe (43-46). These studies have also focused on potential socio-demographic factors, which influence parents' decisions to decline HPV vaccination to their daughters, including age, ethnicity, receipt of childhood vaccines, knowledge, attitudes, parental and community acceptability. Of note, in Greece, a country under financial crisis since 2010, 
in which several health quality indexes have already deteriorated (47), financial reasons have also been elucidated behind non-vaccination against HPV (38). Since data on HPV vaccination among female adolescents in Greece remain limited, the first pilot cross-sectional questionnaire-based study, known as the ELEFTHERIA study, was expected to assess HPV vaccination uptake among female adolescents in Greece during the period between 2008-2014 and to investigate socio-demographic reasons for declining HPV vaccination (38). It was designed by the First Department of Paediatrics at the University of Athens and the Department of Clinical Virology at the University of Crete and its name was inspired by 'Eleftheria', the name of the first adolescent, who was recruited in the study. The preliminary findings of this project stress the need to provide and maintain health insurance coverage to children in countries under financial crisis (38). For this reason, urgent health policy responses to the recent financial collapse in Greece are required as the full impact of austerity measures unfolds in the coming years.

Children and Ebola infection. EV was first discovered in 1976 and has caused three outbreaks, two simultaneously in 1976 and one in 2014 (48). The exact mode of transmission of EV remains unknown; however, it seems to be transmitted from the biological fluids of wild animals and subsquently through human-to-human contact (49). According to the WHO, the 2014 west African outbreak claimed a case fatality, which ranged from 25 to $90 \%$ and a total number of roughly 10,000 fatalities; the number of children is unknown (49). This fact makes it a potential lethal tool in bio-warfare. If used in residential areas or within the public transportation system, as a biological agent, EV can easily affect the welfare and life of children.

Emergency Departments (EDs) should be ready for such attacks, especially catering for the needs of paediatric victims $(50,51)$. Carley's consensus statement for formulating major incident plans can be quite helpful (52). Local tertiary paediatric hospitals or peadiatric units should play an active role by coordinating the care of children. Planning for such events involving children should be carried out by experienced clinicians in Paediatrics. Approximately 10-15\% of the equipment used in general hospitals should be suitable for peadiatric victims of all ages. Staff training for major incidents should be regular and should include caring for children. While triaging, it is advisable to use modified adult scoring systems. In particular, when triaging a large number of children, the Eichelberger modification to the triage revised trauma score should be used (48). If possible, children's assessment and treatment, as well as transfers, when needed, should be provided by experienced paediatric teams. If allowed by the senior clinician, parents could possibly stay on site near their children. During hospitalisation and following discharge, adequate support should be provided to the families (52). An ED should be ready to accommodate the needs of children following an EV attack by offering personal protective equipment (PPE) to staff, appropriate decontamination and isolation facilities and antidotes, if available, as well as general paediatric equipment. Staff should always suspect bioterrorism if a few or several people present with unusual or unexpected symptoms or if their symptoms do not conform with a certain medical diagnosis. Identify, isolate and inform is the current standard approach to EV suspicion (53). Hopefully, none of this will be actually needed in the near future.
Viral bronchiolititis in Paediatric Intensive Care Unit (PICU). Viral bronchiolitis, mainly caused by RSV infection, remains the leading cause of infant admission to the PICU $(54,55)$. Recent laboratory tools have also confirmed many other viruses to account for bronchiolitis, either as co-infection with RSV or as the only aetiological pathogen. Such viruses are HRV, hMPV, adenovirus, as well as influenza and parainfluenza viruses (56). Even following the anti-RSV post-prophylaxis era, RSV seems to be the most common cause of bronchiolitis in infancy and is responsible for severe clinical manifestations, longer hospitalisation and PICU admissions (57). Severe bronchiolitis is indicated by persistently increased respiratory effort (tachypnoea, nasal flaring, intercostal, subcostal or suprasternal retractions, accessory muscle use and grunting) hypoxaemia, apnoea or acute respiratory failure. Risk factors for severe disease and/or complications of bronchiolitis, even death, are considered to be prematurity (gestational age $<37$ weeks), age $<12$ weeks, chronic pulmonary disease, particularly BPD (also known as chronic lung disease), congenital and anatomic defects of the airways, congenital heart disease, immunodeficiency and neurologic disease (58). Though it is a common and old clinical entity, there is a wide variety in clinical practice and the need to clarify each of the therapeutic means has to be done with large, well-designed clinical studies. When it comes to the treatment of critically ill children, there is a paucity of evidence-based guidelines. Fluid replacement, oxygen supplementation and close monitoring are the first steps in the management of the disease. The role of epinephrine and nebulised bronchodilators in combination with systemic corticosteroids is questioned, but can be given on an individualised basis (59). Nebulised hypertonic saline is a new therapeutic agent, which has not been investigated for possible use in the PICU. Although it is recommended, its use remains to be established. Other therapies, such as Heliox, surfactant and ribavirin, are also being examined, with controversial results thus far. As little seems to have been achieved when it comes to treatment, a lot of emphasis has been given to the prevention of the illness. Hygiene measures and education of caregivers, hospital personnel, nurses and doctors on limiting transmission and elimination of the environmental risk factors are strongly recommended in published guidelines (59). Palivizumab prophylaxis is recommended for infants with risk factors, such as chronic illnesses, prematurity and immunodeficiency, as well as other conditions, which are being clarified at the revised published guidelines (59). Since the burden of RSV bronchiolitis is high, research must aim for the development of an anti-RSV vaccine, as well as new antiviral agents.

Vaccination against measles, mumps and rubella (MMR) versus autism. Autism is a severe neurodevelopmental disorder affecting the paediatric population (60). Autism spectrum disorders (ASD) include disorders, such as psychomotor regression, language impairment and behavioural social withdrawal, placing patients with ASD in permanent need for healthcare and social support (61). Earlier reports have associated vaccination against MMR with the occurrence of ASD in children (62), thus leading in particularly low vaccination coverage. As a result, outbreaks regarding the vaccine preventable strains have reappeared throughout Europe $(63-65)$, Asia $(66,67)$ and the United States $(68,69)$. Extensive research around the issue 
has emerged, soundly dissociating MMR vaccination from any ASD occurrence, even in high-risk populations (70-72). However, the loss of credibility of the MMR vaccine remains a concern. This can be partially explained by failure on behalf of the scientific community to effectively communicate: i) the limitations and bias of the original study of Wakefield et al (62) in 1998 , ii) the mounting evidence supporting the lack of a causal relationship between MMR vaccine receipt and autism onset, as proven by large epidemiological studies (70-72) and iii) adverse effects of vaccination in the general setting of coincidental, rather than causal associations. Another contributing factor must be attributed to a powerful influence by the public media, such as television, newspapers and internet, regarding MMR vaccination, ultimately leading to a subsequent negative public health response. In the future, more effective communication strategies are required to reassure parents of vaccine safety and importance.

Ocular viral infections in neonates and children. The ocular manifestations of viral infections in neonates and children vary greatly and can range from innocuous to vision threatening (73). The majority of viral conjunctivitis in children are caused by adenovirus, a DNA virus, which can cause a range of human diseases, including upper respiratory tract infection. Viral conjunctivitis is associated with epidemic keratoconjunctivitis, pharyngoconjunctival fever and acute haemorrhagic conjunctivitis (74). Signs include eyelid oedema and tender pre-auricular lymphadenopathy, prominent conjunctival hyperaemia, follicles and punctate epithelial keratitis. In viral infections in children, the involvement of the anterior segment is mild and self-limited; spontaneous resolution usually occurs within 2-3 weeks, except in cases of congenital infection, which are often associated with significant alterations in ocular structures.

Neonatal conjunctivitis (also known as ophthalmia neonatorum) is defined as conjunctival inflammation developing within the first month of life. It is the most common type of infection in neonates, occurring in up to $10 \%$ of neonates. It is often identified as a specific entity distinct from conjunctivitis in older infants as it is often the result of infection transmitted from the mother to the infant during delivery (74). Molluscum contagiosum ocular infection in children is caused by a specific double-stranded DNA poxvirus, which typically affects otherwise healthy children with a peak incidence between the ages of two and four. Transmission occurs through contact, with subsequent autoinoculation. Presentation is with chronic unilateral ocular irritation and mild discharge, while lesions are usually self-limiting. Primary infection with herpes simplex virus (HSV) is usually associated with eyelid and periorbital vesicles, papillary conjunctivitis, discharge and lid swelling. Dendritic corneal ulcers can also be present, particularly in patients with atopic infection can lead to eczema herpeticum, which can be very severe (75-77). Varicella-zoster virus (VZV) is a serious, but rare, viral infection in children, in which prolonged inflammation may lead to corneal thinning or perforation, glaucoma and cataract formation (74).

Involvement of the posterior structures mostly related to HSV and VZV is potentially sight-threatening. Retinal or optic nerve involvement should be suspected in any child, who complains of an acute onset of blurred vision in the absence of anterior segment inflammation or opacities in the ocular media.
Optic neuropathy may occur as an isolated sign, although it is more often associated with a more generalised involvement of the central nervous system (77,78). While specific therapy is not always available, the early diagnosis of ocular viral disease in children should aid in the amelioration of acute symptoms and in the prevention of long-term complications.

Otorhinolaryngologists versus HPV-associated lesions. HPV is responsible for many benign lesions of the airway tract and the genital area in the adult population, as well as for cancer of the larynx and oral cavity, particularly subtypes 16 and $18(79,80)$. A recent study (81) also revealed an increased frequency of HPV infections in neonates and children. Otorhinolaryngologists are the specialists, who treat children with HPV-related lesions localised in the oral cavity, the oropharynx and larynx. These lesions are mostly benign. There are four types of HPV-related lesions concerning the upper airway track: i) squamous papilloma, ii) verruca vulgaris, iii) focal epithelial hyperplasia and iv) condyloma acuminatum.

In children, the most common clinical expression of HPV is recurrent respiratory papillomatosis (RRP). It causes hoarseness of the voice and sometimes the lesions can cause obstruction of the upper airway track. In adults, the clinical behaviour differs, as the disease requires fewer surgical excisions than in children. In children, the lesions caused by HPV often need many surgical procedures before they become extinct and quiescent. Inverted papilloma, which is a type of squamous papilloma, is strongly associated with HPV subtypes 6 and 1 and its incidence in children is twice as high compared to adults (82). Fortunately, the majority of these lesions can be surgically removed and provide the young patient with a good prognosis. Microsurgery, transoral laser microsurgery (TLM) and endoscopic endonasal approach (EEA) are some of the most frequent surgical methods of excision. A review of recent studies dealing with HPV lesions in children revealed only a few cases, which have been treated surgically. The most common approach of surgical treatment is using TLM. However, laser treatment can cause several complications, such as stenosis, burns of the airway tract and scars. An alternative to TLM are microdebriders (83). Microdebriders provide a more accurate excision, removing only the affected tissue and preserving the healthy tissue. The preservation of healthy epithelium is very useful, when repeated interventions are needed, particularly in children. When the lesion causes obstruction of the airway tract, a tracheotomy is necessary to keep the airway open. However, it should be avoided and performed only when it is an emergency because of the danger of spreading the disease to the respiratory tract (84). In the future, the association between HPV-related lesions in children and cancerous lesions in adults needs to be considered carefully, revealing the importance of vaccination in children against HPV (85).

Immunology of infectious mononucleosis (IM). IM is the main clinical manifestation of Epstein Barr virus (EBV) infection (86). Other agents, such as CMV, toxoplasma and adenovirus, produce a similar illness. The incubation period ranges from 33 to 49 days (87). Clinical presentation is usually prolonged (average 16 days) and ranges from a non-specific flu-like illness to the more distinctive triad 'fever, pharyngitis, lymphadenopathy-splenomegaly'. Other clinical manifesta- 
tions include fatigue, hepatitis and eyelid oedema. Possible complications are meningoencephalitis, haemolytic anaemia, thrombocytopenia, rash, conjunctivitis, haemophagocytic syndrome, myocarditis, neurologic diseases, pancreatitis, parotitis, pericarditis, pneumonitis, psychological disorders and splenic rupture. Laboratory findings include the elevation of liver enzymes and lymphocytosis with a marked increase in the number of atypical lymphocytes in the peripheral blood (87). Additionally, immunophenotypic alterations of lymphocytes have been described in the various phases of EBV infection (88). More specifically, a reduction of B-lymphocytes and an increase in the number of $\mathrm{CD}^{+} \mathrm{CD} 8^{+}, \mathrm{T}$-lymphocytes, with a subsequent decrease in the $\mathrm{CD}^{+} \mathrm{CD} 4^{+} / \mathrm{CD}^{+} \mathrm{CD}^{+}$ratio is noted (89).

In the study by Panagopoulou et al (86), which was presented at the Workshop, researchers aimed to examine whether there is an association between the immunophenotypic alterations and the variability of the clinical presentation of IM. Although several studies (89-91) have examined the immunophenotype of lymphocytes in EBV infection, very few (89) have correlated these with the clinical course. The presented study (86) showed that the immunophenotypic analysis of cytotoxic $\mathrm{T}$ cells provides important information on the physiology of the immune response to EBV infection. Additionally, it may potentially play a predicting role, providing information on the expected clinical course, potential complications and the time to recovery from EBV infection.

Merkel cell polyomavirus (MCPyV): A novel emerging virus of childhood. MCPyV is a newly-discovered small, human DNA virus, which causes a widespread, previously unrecognised, human infection in adulthood and childhood $(92,93)$. It is classified in the family Polyomaviridae, a group of non-enveloped, double-stranded DNA viruses with icosahedral symmetry, which can infect a variety of vertebrates, including humans and can cause malignant tumours upon their inoculation into heterologous hosts (94). First described in January 2008, the prototype sequence of $\mathrm{MCPyV}$ has a 5,387 base pair genome and contains the early region, which encodes the large tumor (LT) antigen and the small tumour (sT) antigen and the alternative tumor antigen open reading frame (ALTO), the late region, which encodes VP 1, VP 2 and VP 3 and a non-coding regulatory region. Of note, the genome of $\mathrm{MCPyV}$ has been detected in approximately $80 \%$ of Merkel cell carcinoma (MCC) cases (95). Although MCC is a relatively rare, highly aggressive, human skin cancer of neuroendocrine origin, its worldwide incidence has increased over the past twenty years from 500 to 1,500 cases per year. In the majority of MCC cases, MCPyV is integrated into the host genome in a monoclonal manner and the viral $\mathrm{T}$ antigen has truncating mutations, which render the $\mathrm{T}$ antigen unable to initiate the DNA replication required to propagate the virus (94).

Recent serological data using enzyme-linked immunosorbent assay (ELISA) techniques have suggested that MCPyV infection is common in childhood and occurs during early childhood, after the disappearance of specific maternal antibodies against MCPyV (93). MCPyV DNA has been detected in nasopharyngeal aspirate samples collected from children, indicating the presence of $\mathrm{MCPyV}$ in the upper respiratory tract of children $(96,97)$. MCPyV is acquired in childhood through close contact involving saliva and the skin (93). As to date, the mode of MCPyV transmission has not been fully elucidated, the precise role of the respiratory secretions in MCPyV transmission in childhood requires further investigation. The respiratory tract system is involved as a unique reservoir of MCPyV in children and respiratory secretions seem to play a significant role in MCPyV transmission in childhood. Moreover, future studies are required in order to fully elucidate the potential implications of MCPyV infection in neoplasms in children.

\section{Acknowledgements}

The authors would like to thank all of the chair persons and the speakers of the Workshop on Paediatric Virology for their continued support in providing the most up-to-date information to the symposium. The authors would also like to thank the participants, who attended the event and provided feedback so that further study on improving the program can be achieved for the future. Last but not least, this symposium would not have been possible without the dedicated hard work and strong commitment from the Congress Secretary Carol Kalogridis, the members of the PVSG and the whole symposium organising team for developing the scientific program, organising, coordinating and guaranteeing the success of this scientific event.

\section{References}

1. Shulman ST: The history of pediatric infectious diseases. Pediatr Res 55: 163-176, 2004

2. Starr M: Paediatric infectious diseases: The last 50 years. J Paediatr Child Health 51: 12-15, 2015.

3. Portnoy B: Pediatric Virology. Calif Med 102: 431-445, 1965.

4. Lannon CM and Peterson LE: Pediatric collaborative networks for quality improvement and research. Acad Pediatr 13 (Suppl 6): S69-S74, 2013.

5. Theodoridou M: Professional and ethical responsibilities of health-care workers in regard to vaccinations. Vaccine 32: 4866-4868, 2014.

6. Stoddard JJ, Cull WL, Jewett EA, Brotherton SE, Mulvey HJ and Alden ER: Providing pediatric subspecialty care: A workforce analysis. AAP Committee on Pediatric Workforce Subcommittee on Subspecialty Workforce. Pediatrics 106: 1325-1333, 2000.

7. Global Pediatric Education Consortium: The Global Pediatric Education Consortium: Transforming pediatric training and child health through collaboration. Pediatr Int 52: 684-686, 2010.

8. 20th World Congress on Advances in Oncology and 18th International Symposium on Molecular Medicine, October 8-10, 2015, Metropolitan Hotel, Athens, Greece. http://www.spandidos-publications.com

9. Mammas I, Breen L, Rackham O and Hughes A: Congenital cytomegalovirus (CMV) infection in twins born by a CMV-negative mother. Acta Paediatr 97: 264, 2008.

10. Mammas IN, Sourvinos G and Spandidos DA: The paediatric story of human papillomavirus (Review). Oncol Lett 8: 502-506, 2014.

11. Greenough A, Drysdale S, Broughton S and Bont L: The impact of viral infections on the long-term outcomes of prematurely born infants. Int J Mol Med 36: S89, 2015.

12. Greenough A, Alexander J, Boit P, Boorman J, Burgess S, Burke A, Chetcuti PA, Cliff I, Lenney W, Lytle T, et al: School age outcome of hospitalisation with respiratory syncytial virus infection of prematurely born infants. Thorax 64: 490-495, 2009.

13. Shefali-Patel D, Paris MA, Watson F, Peacock JL, Campbell M and Greenough A: RSV hospitalisation and healthcare utilisation in moderately prematurely born infants. Eur J Pediatr 171: 1055-1061, 2012.

14. Broughton S, Roberts A, Fox G, Pollina E, Zuckerman M, Chaudhry S and Greenough A: Prospective study of healthcare utilisation and respiratory morbidity due to RSV infection in prematurely born infants. Thorax 60: 1039-1044, 2005. 
15. Drysdale SB, Lo J, Prendergast M, Alcazar M, Wilson T, Zuckerman M, Smith M, Broughton S, Rafferty GF, Peacock JL, et al: Lung function of preterm infants before and after viral infections. Eur J Pediatr 173: 1497-1504, 2014

16. Drysdale SB, Alcazar-Paris M, Wilson T, Smith M,Zuckerman M, Peacock JL, Johnston SL and Greenough A: Viral lower respiratory tract infections and preterm infants' healthcare utilisation. Eur J Pediatr 174: 209-215, 2015.

17. Drysdale SB, Wilson T, Alcazar M, Broughton S, Zuckerman M, Smith M, Rafferty GF, Johnston SL and Greenough A: Lung function prior to viral lower respiratory tract infections in prematurely born infants. Thorax 66: 468-473, 2011.

18. Drysdale SB, Prendergast M, Alcazar M, Wilson T, Smith M, Zuckerman M, Broughton S, Rafferty GF, Johnston SL, Hodemaekers HM, et al: Genetic predisposition of RSV infection-related respiratory morbidity in preterm infants. Eur J Pediatr 173: 905-912, 2014.

19. Drysdale SB, Alcazar-Paris M, Wilson T, Smith M,Zuckerman M, Broughton S, Rafferty GF, Peacock JL, Johnston SL and Greenough A: Rhinovirus infection and healthcare utilisation in prematurely born infants. Eur Respir J 42: 1029-1036, 2013.

20. Theodoridou M: Defeating polio: Vaccine anniversary (1955-2015). Int J Mol Med 36: S89, 2015.

21. WHO: Polio vaccines: WHO position paper, January 2014 - recommendations. Vaccine 32: 4117-4118, 2014.

22. European Centre for Disease Prevention and control: Risk assessment: Wild-type poliovirus 1 transmission in Israel - what is the risk to the EU/EEA? ECDC, Stockholm, 2013.

23. European Centre for Disease Prevention and Control: Rapid risk assessment: Suspected outbreak of poliomyelitis in Syria: Risk of importation and spread of poliovirus in the EU. ECDC, Stockholm, 2013.

24. Global Polio Eradication Initiative: Data and monitoring. http://www.polioeradication.org.

25. Porter KA, Diop OM, Burns CC, Tangermann RH and Wassilak SG: Tracking progress toward polio eradication - worldwide, 2013-2014 MMWR Morb Mortal Wkly Rep 64: 415-420, 2015.

26. Orenstein WA; Committee on Infectious Diseases: Eradicating polio: how the world's pediatricians can help stop this crippling illness forever. Pediatrics 135: 196-202, 2015

27. Kramvis A: The clinical implications of hepatitis B virus genotypes in Paediatrics. Int J Mol Med 36: S89, 2015.

28. World Health Organization: Hepatitis B. Fact sheet No. 204 Updated July 2015. http://www.who.int/mediacentre/factsheets/fs204/en/.

29. Ni YH: Natural history of hepatitis B virus infection: pediatric perspective. J Gastroenterol 46: 1-8, 2011.

30. Lok AS and McMahon BJ: Chronic hepatitis B. Hepatology 45: 507-539, 2007.

31. Milich D and Liang TJ: Exploring the biological basis of hepatitis B e antigen in hepatitis B virus infection. Hepatology 38 : 1075-1086, 2003.

32. Hsu HY, Chang MH, Hsieh KH, Lee CY, Lin HH, Hwang LH, Chen PJ and Chen DS: Cellular immune response to HBcAg in mother-to-infant transmission of hepatitis B virus. Hepatology 15 : 770-776, 1992.

33. Chen M, Sällberg M, Hughes J, Jones J, Guidotti LG, Chisari FV, Billaud JN and Milich DR: Immune tolerance split between hepatitis B virus precore and core proteins. J Virol 79: 3016-3027, 2005.

34. Beasley RP, Trepo C, Stevens CE and Szmuness W: The e antigen and vertical transmission of hepatitis B surface antigen. Am J Epidemiol 105: 94-98, 1977.

35. Okada K, Kamiyama I, Inomata M, Imai M, Miyakawa $Y$ and Mayumi M: e antigen and anti-e in the serum of asymptomatic carrier mothers as indicators of positive and negative transmission of hepatitis B virus to their infants. N Engl J Med 294: 746-749, 1976.

36. Tong MJ, Thursby MW, Lin JH, Weissman JY and McPeak CM: Studies on the maternal-infant transmission of the hepatitis B virus and HBV infection within families. Prog Med Virol 27: 137-147, 1981.

37. Kramvis A: Genotypes and genetic variability of hepatitis B virus. Intervirology 57: 141-150, 2014

38. Mammas IN, Sourvinos G, Theodoridou M and Spandidos DA: Understanding the factors affecting human papillomavirus vaccination acceptance among adolescents. Int J Mol Med 36: S90, 2015.

39. Mammas IN and Spandidos DA: George N. Papanicolaou (1883-1962): Fifty years after the death of a great doctor, scientist and humanitarian. J BUON 17: 180-184, 2012
40. Tota JE, Chevarie-Davis M, Richardson LA, Devries M and Franco EL: Epidemiology and burden of HPV infection and related diseases: Implications for prevention strategies. Prev Med 53 (Suppl 1): S12-S21, 2011.

41. zur Hausen H: Papillomaviruses and cancer: From basic studies to clinical application. Nat Rev Cancer 2: 342-350, 2002.

42. Kahn JA: HPV vaccination for the prevention of cervical intraepithelial neoplasia. N Engl J Med 361: 271-278, 2009.

43. Fagot JP, Boutrelle A, Ricordeau P, Weill A and Allemand H: HPV vaccination in France: uptake, costs and issues for the National Health Insurance. Vaccine 29: 3610-3616, 2011.

44. Deleré Y, Böhmer MM, Walter D and Wichmann O: HPV vaccination coverage among women aged 18-20 years in Germany three years after recommendation of HPV vaccination for adolescent girls: results from a cross-sectional survey. Hum Vaccin Immunother 9: 1706-1711, 2013.

45. Steens A, Wielders CC, Bogaards JA, Boshuizen HC, de Greeff SC and de Melker HE: Association between human papillomavirus vaccine uptake and cervical cancer screening in the Netherlands: Implications for future impact on prevention. Int J Cancer 132: 932-943, 2013.

46. Fisher H, Audrey S, Mytton JA, Hickman M and Trotter C: Examining inequalities in the uptake of the school-based HPV vaccination programme in England: a retrospective cohort study. J Public Health (Oxf) 36: 36-45, 2014

47. Vandoros S, Hessel P, Leone T and Avendano M: Have health trends worsened in Greece as a result of the financial crisis? A quasi-experimental approach. Eur J Public Health 23: 727-731, 2013.

48. Christaki I, Beattie T and Midgley P: The challenge of modern biowarfare: ED preparedness for paediatric victims of the Ebola virus. Int J Mol Med 36: S90, 2015.

49. Elshabrawy HA, Erickson TB and Prabhakar BS: Ebola virus outbreak, updates on current therapeutic strategies. Rev Med Virol 25: 241-253, 2015

50. Venkat A, Asher SL, Wolf L, et al; American College of Emergency Physicians; Emergency Nurses Association; Society for Academic Emergency Medicine: Ethical issues in the response to Ebola virus disease in United States emergency departments: A position paper of the American College of Emergency Physicians, the Emergency Nurses Association, and the Society for Academic Emergency Medicine. Acad Emerg Med 22: 605-615, 2015.

51. Bogucki S and Isakov A: Patients under investigation for Ebola virus disease in the United States: hospital preparedness planning and alternate care facilities. Acad Emerg Med 22: 600-604, 2015.

52. Mackway-Jones K, Carley SD and Robson J: Planning for major incidents involving children by implementing a Delphi study. Arch Dis Child 80: 410-413, 1999.

53. Richardson KJ: Ebola virus disease. Adv Emerg Nurs J 37: 102-115, 2015.

54. Koutsaftiki C: The clinical profile of infants with RSV bronchiolitis in PICU. Int J Mol Med 36: S90, 2015.

55. Koutsaftiki C, Tsialla A, Sideri G, Bampanelou A, Papadatos I and Sianidou L: Management of infants with severe bronchiolitis who were admitted to two PICUs. Int J Mol Med 36: S91, 2015.

56. Bamberger E, Srugo I, Abu Raya B, Segal E, Chaim B, Kassis I, Kugelman A and Miron D: What is the clinical relevance of respiratory syncytial virus bronchiolitis?: Findings from a multi-center, prospective study. Eur J Clin Microbiol Infect Dis 31: 3323-3330, 2012

57. Eggleston HA, Gunville CF, Miller JI, Sontag MK and Mourani PM: A comparison of characteristics and outcomes in severe human metapneumovirus and respiratory syncytial virus infections in children treated in an intensive care unit. Pediatr Infect Dis J 32: 1330-1334, 2013

58. Hasegawa K, Pate BM, Mansbach JM, Macias CG, Fisher ES, Piedra PA, Espinola JA, Sullivan AF and Camargo CA Jr: Risk factors for requiring intensive care among children admitted to ward with bronchiolitis. Acad Pediatr 15: 77-81, 2015.

59. Ralston SL, Lieberthal AS, Meissner HC, et al: Clinical practice guideline: the diagnosis, management, and prevention of bronchiolitis. Pediatrics 134: e1474-e1502, 2014.

60. Koutsaki M: MMR vaccination and autism: An update. Int J Mol Med 36: S91, 2015

61. Rapin I and Tuchman RF: Autism: Definition, neurobiology, screening, diagnosis. Pediatr Clin North Am 55: 1129-1146, viii, 2008

62. Wakefield AJ, Murch SH, Anthony A, Linnell J, Casson DM, Malik M, Berelowitz M, Dhillon AP, Thomson MA, Harvey P, et al: Ileal-lymphoid-nodular hyperplasia, non-specific colitis, and pervasive developmental disorder in children. Lancet 351: 637-641, 1998. 
63. Piccirilli G, Lazzarotto T, Chiereghin A, Serra L, Gabrielli L and Lanari M: Spotlight on measles in Italy: why outbreaks of a vaccine-preventable infection continue in the 21 st century. Expert Rev Anti Infect Ther 13: 355-362, 2015.

64. Maillet $M$, Bouvat $E$, Robert N, Baccard-Longère $M$, Morel-Baccard C, Morand P, Vabret A and Stahl JP: Mumps outbreak and laboratory diagnosis. J Clin Virol 62: 14-19, 2015.

65. Pegorie M, Shankar K, Welfare WS, Wilson RW, Khiroya C, Munslow G, Fiefield D, Bothra V and McCann R: Measles outbreak in Greater Manchester, England, October 2012 to September 2013: epidemiology and control. Euro Surveill 19: pii: 20982, 2014

66. Ryu JU, Kim EK, Youn YS, Rhim JW and Lee KY: Outbreaks of mumps: An observational study over two decades in a single hospital in Korea. Korean J Pediatr 57: 396-402, 2014.

67. Centers for Disease Control and Prevention (CDC): Nationwide rubella epidemic - Japan, 2013. MMWR Morb Mortal Wkly Rep 62: 457-462, 2013.

68. Gahr P, DeVries AS, Wallace G, et al: An outbreak of measles in an undervaccinated community. Pediatrics 134: e220-e228, 2014

69. Kutty PK, Lawler J, Rausch-Phung E, et al: Epidemiology and the economic assessment of a mumps outbreak in a highly vaccinated population, Orange County, New York, 2009-2010. Hum Vaccin Immunother 10: 1373-1381, 2014.

70. Jain A, Marshall J, Buikema A, Bancroft T, Kelly JP and Newschaffer CJ: Autism occurrence by MMR vaccine status among US children with older siblings with and without autism. JAMA 313: 1534-1540, 2015.

71. Uno Y, Uchiyama T, Kurosawa M, Aleksic B and Ozaki N: Early exposure to the combined measles-mumps-rubella vaccine and thimerosal-containing vaccines and risk of autism spectrum disorder. Vaccine 33: 2511-2516, 2015.

72. Taylor LE, Swerdfeger AL and Eslick GD: Vaccines are not associated with autism: An evidence-based meta-analysis of case-control and cohort studies. Vaccine 32: 3623-3629, 2014.

73. Portaliou D: Ocular viral infections in neonates and children. Int J Mol Med 36: S91, 2015

74. Matoba A: Ocular viral infections. Pediatr Infect Dis 3: 358-368, 1984.

75. Corey L and Wald A: Maternal and neonatal herpes simplex virus infections. N Engl J Med 361: 1376-1385, 2009.

76. Sanders JE and Garcia SE: Pediatric herpes simplex virus infections: an evidence-based approach to treatment. Pediatr Emerg Med Pract 11: 1-19, quiz 19, 2014

77. Fong CY, Aye AM, Peyman M, Nor NK, Visvaraja S, Tajunisah I and Ong LC: Neonatal herpes simplex virus type-1 central nervous system disease with acute retinal necrosis. Pediatr Infect Dis J 33: 424-426, 2014.

78. Modrzejewska M,Lachowicz E, Karczewicz D and Zdanowska A Chorioretinitis in infants. Klin Oczna 113: 352-356, 2011

79. Kostagianni G: HPV infections in children: Current surgical treatment of HPV lesions found in the oral cavity, oropharynx, larynx and nose cavity. Int J Mol Med 36: S90, 2015.

80. Marur S, D'Souza G, Westra WH and Forastiere AA: HPV-associated head and neck cancer: a virus-related cancer epidemic. Lancet Oncol 11: 781-789, 2010.

81. Krüger M, Pabst AM, Walter C, Sagheb K, Günther C, Blatt S, Weise K, Al-Nawas B and Ziebart T: The prevalence of human papilloma virus (HPV) infections in oral squamous cell carcinomas: a retrospective analysis of 88 patients and literature overview. J Craniomaxillofac Surg 42: 1506-1514, 2014.
82. Summersgill KF, Smith EM, Levy BT, Allen JM, Haugen TH and Turek LP: Human papillomavirus in the oral cavities of children and adolescents. Oral Surg Oral Med Oral Pathol Oral Radiol Endod 91: 62-69, 2001.

83. Stamataki S, Nikolopoulos TP, Korres S, Felekis D, Tzangaroulakis A and Ferekidis E: Juvenile recurrent respiratory papillomatosis: still a mystery disease with difficult management. Head Neck 29: 155-162, 2007.

84. Carifi M, Napolitano D, Morandi M and Dall'Olio D: Recurrent respiratory papillomatosis: Current and future perspectives. Ther Clin Risk Manag 11: 731-738, 2015.

85. Wierzbicka M, Józefiak A, Jackowska J, Szydłowski J and Goździcka-Józefiak A: HPV vaccination in head and neck HPV-related pathologies. Otolaryngol Pol 68: 157-173, 2014.

86. Panagopoulou P, Fleva A, Papadopoulou-Alataki E, Pavlitou-Tsiontsi A and Emporiadou-Petikopoulou $\mathrm{M}$ : Correlation between the clinical course and the immunophenotypic profile of T-cytotoxic lymphocytes in children with infectious mononucleosis. Int J Mol Med 36: S92, 2015.

87. Odumade OA, Hogquist KA and Balfour HH Jr: Progress and problems in understanding and managing primary Epstein-Barr virus infections. Clin Microbiol Rev 24: 193-209, 2011.

88. Scherrenburg J, Piriou ER, Nanlohy NM and van Baarle D: Detailed analysis of Epstein-Barr virus-specific CD4+ and CD8+ $\mathrm{T}$ cell responses during infectious mononucleosis. Clin Exp Immunol 153: 231-239, 2008

89. Papadopoulou-Alataki E, Fleva A, Antari V, Pavlitou-Tsiontsi A, Moskofidis M and Varlamis G: Study of the immunophenotype of peripheral blood lymphocyte subsets in children with Epstein-Barr virus and cytomegalovirus infection: Association with outcome. Paidiatriki 71: 135-140, 2008.

90. Hamann D, Baars PA, Rep MH, Hooibrink B, Kerkhof-Garde SR, Klein MR and van Lier RA: Phenotypic and functional separation of memory and effector human CD8+ T cells. J Exp Med 186: 1407-1418, 1997.

91. Hudnall SD, Patel J, Schwab H and Martinez J: Comparative immunophenotypic features of EBV-positive and EBV-negative atypical lymphocytosis. Cytometry B Clin Cytom 55: 22-28, 2003.

92. Sourvinos G, Mammas IN and Spandidos DA: Merkel cell polyomavirus (MCPyV): A novel emerging virus of infancy and childhood. Int J Mol Med 36: S91, 2015.

93. Sourvinos G, Mammas IN and Spandidos DA: Merkel cell polyomavirus infection in childhood: current advances and perspectives. Arch Virol 160: 887-892, 2015.

94. zur Hausen H: Novel human polyomaviruses - re-emergence of a well known virus family as possible human carcinogens. Int J Cancer 123: 247-250, 2008

95. Ehlers B and Wieland U: The novel human polyomaviruses HPyV6, 7, 9 and beyond. APMIS 121: 783-795, 2013

96. Goh S, Lindau C, Tiveljung-Lindell A and Allander T: Merkel cell polyomavirus in respiratory tract secretions. Emerg Infect Dis 15: 489-491, 2009.

97. Abedi Kiasari B, Vallely PJ and Klapper PE: Merkel cell polyomavirus DNA in immunocompetent and immunocompromised patients with respiratory disease. J Med Virol 83: 2220-2224, 2011. 